\title{
Formação em Psicologia no Brasil: Um Perfil dos Cursos de Graduação
}

\author{
Psychology Education in Brazil: \\ A Profile of Undergraduation Programs \\ Formación en Psicología en Brasil: \\ Un Perfil de Los Cursos de Graduación
}

Felipe Stephan Lisboa

Universidade Federal de

Viçosa

Altemir José Gonçalves

Barbosa

Universidade Federal de

Juiz de fora 
Resumo: Para caracterizar os cursos de graduação em Psicologia no Brasil, efetuou-se um estudo documental utilizando informações de domínio público contidas no Cadastro das Instituições de Ensino Superior do Ministério da Educação. Dos 396 cursos identificados, em sua totalidade presenciais, grande parte se encontra em instituições universitárias privadas com fins lucrativos localizadas predominantemente em cidades no interior do País e na Região Sudeste. Majoritariamente, funcionam em turnos parciais, têm duração de 10 semestres e carga horária de cerca de 4.000 horas, adotam o regime letivo semestral e, nas avaliações nacionais, obtiveram o conceito médio. Evidencia-se uma enorme, rápida e desordenada expansão dos cursos de graduação, especialmente a partir da década de 1990. Alerta-se, dessa forma, para que sejam tomadas medidas urgentes no sentido de aliar quantidade e qualidade no ensino da Psicologia no Brasil.

Palavras-chave: Ensino de Psicologia. Cursos de graduação. Formação inicial de psicólogos. História da Psicologia no Brasil.

Abstract: A documental study was made to describe Brazilian psychology undergraduation programs using public information available in a Ministry of Education's Database of undergraduation institutions. 396 programs were identified and most of them were held in private universities with profit objectives located in the interior of the country and in the southern-eastern region. The classes are taught in a single period of the day, their duration is 10 semesters and their timetable has 4000 hours. The programs usually adopt the half-year term and had medium scores in national exams. A huge, quick and disorderly expansion of the undergraduation programs has been evidenced, especially from the 90 decade on. Urgent actions need to be implemented on to ally quantity and quality in the Brazilian psychology education.

Keywords: Psychology teaching. Undergraduation programs. Pre-service psychologists' education. History of psychology in Brazil.

Resumen: Para caracterizar los cursos de graduación en Psicología en Brasil, se efectuó un estudio documental utilizando informaciones de dominio público contenidas en el Registro de las Instituciones de Enseñanza Superior del Ministerio de la Educación. De los 396 cursos identificados, en su totalidad presenciales, gran parte se encuentra en instituciones universitarias privadas con fines lucrativos localizadas predominantemente en ciudades en el interior del País y en la Región Sudeste. Mayoritariamente, funcionan en turnos parciales, tienen duración de 10 semestres y carga horaria de cerca de 4.000 horas, adoptan el régimen lectivo semestral y, en las evaluaciones nacionales, lograron el concepto medio. Se evidencia una enorme, rápida y desordenada expansión de los cursos de graduación, especialmente desde la década de 1990. Se alerta, de esa forma, para que sean tomadas medidas urgentes en el sentido de aliar cantidad y calidad en la enseñanza de la Psicología en Brasil.

Palabras clave: Enseñanza de Psicología. Cursos de graduación. Formación inicial de psicólogos. Historia de la Psicología en Brasil.

O presente artigo tem como meta principal caracterizar os cursos de graduação em Psicologia do Brasil, porém não se restringe ao momento atual e nem à descrição isoladamente, pois tem como base o pressuposto que, para compreender o presente e planejar o futuro, há que se conhecer o passado. Assim, inicialmente, efetua uma revisão da história do ensino na área e uma breve reflexão sobre a qualidade da formação inicial ofertada aos psicólogos brasileiros.

O estado atual da arte no ensino de graduação em Psicologia é apresentado a partir de um estudo documental. Foram utilizados dados do Cadastro das Instituições de Ensino Superior do Ministério da Educação (MEC) bem como informações do Exame Nacional de Desempenho dos Estudantes (ENADE).

Retomar o passado do ensino de Psicologia no País e estabelecer um panorama da formação inicial ofertada aos psicólogos brasileiros na atualidade permitiram formular alguns apontamentos para o futuro dos cursos de graduação na área. "Examinar um campo de conhecimento a partir de um ponto de vista que contemple o seu passado, presente e futuro oferece a oportunidade para uma jornada intelectual especial, ao mesmo tempo estimulante e desafiadora" (Rivlin, 2003, p. 215). 


\section{Ensino de Psicologia no Brasil: uma perspectiva histórica}

No Brasil, o ensino de Psicologia, enquanto disciplina autônoma, teve início na segunda metade do século XIX. Anteriormente, conforme relata Massimi (1990, p. 30), "a 'psychologia' comparece como objeto de estudo e de ensino no âmbito de diversas áreas teóricas (Filosofia, Direito, Medicina, Pedagogia, teologia moral)". Assim, no início do século XIX, a Psicologia é ensinada na Faculdade de Direito de São Paulo como "parte de uma mais abrangente 'ciência do homem', cujo fundamento está na fisiologia (ou 'física da natureza humana')" (p. 31). Já nos Seminários Episcopais e nas escolas de formação religiosa, a Psicologia aparece "seja como disciplina especulativa - parte da metafísica... - seja como conhecimento prático do comportamento humano no âmbito da teologia moral" (p. 33).

A situação começa a mudar com o surgimento, ainda na segunda metade do século XIX, das escolas normais, instituições que tinham como objetivo, segundo Massimi (1990, p. 36), "formar um corpo docente competente e adequado às necessidades do sistema educacional brasileiro". Seus alunos eram instruídos a partir de uma metodologia científica de ensino, inspirada nos modelos europeus e norte-americanos. Com as escolas normais, inicia-se a "era normalista", que, segundo Cabral (2004, p. 49), "precedeu a era universitária no ensino da Psicologia".

A partir da Reforma Benjamin Constant, efetuada em 1890, amplia-se a incorporação de disciplinas de Psicologia à grade curricular das escolas normais (Massimi, 1990). De acordo com a autora, é nesse momento que "a pedagogia das escolas normais encontrará seu fundamento na Psicologia experimental recém-surgida" (p. 36). Assim, em 1893, na Escola Normal de São Paulo, a disciplina
Psicologia torna-se obrigatória, o que ocorre em nível nacional somente em 1928. Mais à frente, em 1932, a Escola Normal do Rio de Janeiro é transformada por Anísio Teixeira no Instituto de Educação, cuja direção inicial ficou a cargo de Lourenço Filho (Antunes, 2003). Nesse local, são realizados "cursos de especialização e aperfeiçoamento para diretores e orientadores de ensino", nos quais figuram disciplinas de Psicologia (Lourenço Filho, 2004, p. 87). Segundo Pfromm Netto (2004, p. 160) "muitos daqueles que se dedicaram posteriormente à pesquisa e ao ensino universitários de Psicologia formaramse nas escolas normais e nelas iniciaram suas carreiras".

Também em 1890 é constituído, no Rio de Janeiro, o Pedagogium, instituto que, segundo Schwartzman (1979 como citado por Centofanti, 2004, p. 177), tinha como finalidade "servir como órgão central de coordenação das atividades pedagógicas do País", além de atuar como "centro propulsor das reformas e melhoramentos de que carecesse a educação nacional" (Decreto $n^{\circ}$ 667, de 16/08/1890, como citado por Penna, 1992, p. 56). Nesse espaço, em 1906, é criado por José Joaquim Medeiros e Alburquerque um "bem aparelhado laboratório de Psicologia experimental" (Olinto, 2004, p. 26), que, segundo Antunes (2003), é provavelmente o primeiro laboratório de Psicologia do País. Sob direção de Manoel Bomfim, esse laboratório funcionou por mais de 15 anos e gerou um grande número de pesquisas, algumas delas publicadas na revista Educação e Pediatria (Lourenço Filho, 2004). Além disso, segundo Massimi (1990), o laboratório organizou, nesse período, uma série de cursos de aperfeiçoamento e conferências voltados para estudantes e normalistas. Em 1919, por decreto municipal, o Pedagogium foi extinto. Segundo Penna (1992), essa instituição se perpetuou com a criação, anos mais tarde, do Instituto Nacional de Estudos Pedagógicos (INEP), instituído pelo Decreto-Lei n ${ }^{\circ} 580$, 
de 30/07/1938, e dirigido inicialmente por Lourenço Filho.

Para Penna (1992, p. 22), "as referências ao Pedagogium, à Escola Normal e ao Instituto de Educação revelam-se inteiramente pertinentes na medida em que foram as instituições onde, de fato, se iniciou de modo sistemático o ensino da Psicologia no Brasil".

Em 1923, houve a criação do Laboratório de Psicologia da Colônia de Psicopatas do Engenho de Dentro (Centofanti, 2004; Esch \& Jacó-Vilela, 2001). Segundo os autores, sob direção do polonês Waclaw Radeki, esse laboratório foi transformado, em 1931, no Instituto de Psicologia do Ministério da Educação e Saúde Pública, tendo como objetivos, além da realização de pesquisas científicas e aplicações práticas, a efetivação de uma escola superior de Psicologia. Bernardes (2004) destaca que o projeto desse curso de Psicologia, idealizado por Radeki, foi o primeiro documento de domínio público sobre a formação em Psicologia no Brasil. Para Centofanti (2004), "grosso modo, o curso profissional que Radeki e seus assistentes planejaram em 1932 não era muito diferente dos que encontramos hoje nas faculdades de Psicologia espalhadas pelo País" (p. 192). Seu objetivo não foi atingido, em função do fechamento do Instituto em menos de um ano de atividades, possivelmente em função da escassez de recursos financeiros, além da pressão de grupos médicos e católicos (Centofanti, 2004). Em 1933, o Instituto foi reaberto e incorporado, quatro anos mais tarde, à Universidade do Brasil, atual Universidade Federal do Rio de Janeiro, UFRJ (Penna, 1992).

Na década de 1930, finalmente ocorre a efetiva inserção da Psicologia no ensino superior. Com a criação da primeira universidade do País, a Universidade de São Paulo (USP), em 1934, o Instituto de Educação Caetano de Campos (antiga Escola Normal de
São Paulo) é transformado na Faculdade de Filosofia, Ciências e Letras da USP. Com isso, o Laboratório de Psicologia Educacional do Instituto de Educação é incorporado à cátedra de Psicologia educacional. Também a partir de 1934, na USP, a Psicologia torna-se disciplina obrigatória durante os três anos dos cursos de Filosofia, Ciências Sociais e Pedagogia, além de estar inserida na grade curricular de todos os cursos de licenciatura. Fora de São Paulo, a Psicologia também mostrava sua força no meio universitário, com destaque para as Universidades do Brasil, Católica e Federal de Minas Gerais e Federal do Rio Grande do Sul. Em função dessa crescente inserção da Psicologia no ensino superior é que o período de 1934 até 1962 é denominado período universitário (Pessotti, 2004).

Inicialmente incorporada na formação de outros profissionais, a Psicologia não teve, nesse primeiro momento, um caráter profissionalizante. A disciplina era considerada um conhecimento relevante, um "elemento acessório ou complementar" à formação de diversos profissionais afins (Lourenço Filho, 1957, como citado por Rosas, Rosas, \& Xavier, 1988, p. 32), e ainda não gozava de autonomia no meio acadêmico para oferecer um curso superior independente. A situação começou a mudar em 1946, com o lançamento da Portaria no 272, referente ao Decreto-Lei no 9.092, que institucionalizou a formação do psicólogo brasileiro (Pereira \& Pereira Neto, 2003). Segundo os autores, o profissional "habilitado legalmente deveria freqüentar os três primeiros anos de Filosofia, biologia, fisiologia, antropologia ou estatística e fazer então os cursos especializados de Psicologia. Com a formação dos denominados especialistas em Psicologia, iniciou-se oficialmente o exercício dessa profissão" (p. 23). Tais "cursos especializados", voltados para graduados de cursos como Filosofia e Pedagogia, eram predominantemente de curta duração e "não obedeciam a qualquer norma oficialmente estabelecida, com validade 
nacional assegurada" (Rosas et al, 1988, p. 34). Dessa forma, apesar de representar um avanço rumo à autonomização da Psicologia, o Decreto-Lei no 9.092 não modificou o caráter difuso e superficial da formação dos psicólogos.

\section{Concomitantemente a isso,}

consultórios, gabinetes, serviços, institutos, centros destinados a diversos campos da Psicologia aplicada vinham funcionando em quase todo o Brasil ou vinham sendo instalados nos anos subseqüentes. Os meios de controle da qualificação de seus responsáveis eram praticamente inexistentes. Urgia a adoção de políticas que viabilizassem a formação adequada e o controle da prática psicológica, em defesa da população e da própria imagem da profissão. (Rosas et al., 1988, p. 33)

Nesse sentido, durante toda a década de 50, foram dados importantes passos rumo à regulamentação da formação e da atuação profissional do psicólogo (Rosas et al., 1988). De acordo com os autores, inúmeros eventos e publicações de Psicologia e áreas afins proporcionaram debates sobre o assunto. Segundo Esch e Jacó-Vilela (2001), atendendo a essa movimentação, o Conselho Nacional de Educação solicita às entidades de Psicologia sugestões relativas à regulamentação. Dessa forma, surge, em 1953, uma resposta concreta para a solicitação do Conselho: é elaborado pela Associação Brasileira de Psicotécnica (ABP) e pelo Instituto de Seleção e Orientação Profissional da Fundação Getúlio Vargas (ISOP/ FGV) o primeiro anteprojeto de lei referente à regulamentação da formação e da profissão dos "psicologistas" (Esch \& Jacó-Vilela, 2001). Contudo, em 1958, chega à Câmara dos Deputados o Anteprojeto de Lei $n^{\circ} 3.825$, elaborado pelo Ministério da Educação (MEC) em substituição ao anteprojeto pioneiro. Insatisfeita, a recém-criada Associação Brasileira de Psicólogos confecciona uma proposta substitutiva, que, por sua vez, não agrada ao MEC (Rosas et al., 1988). Por tudo isso, a lei não é aprovada (Rosas et al., 1988). Esch e Jacó-Vilela (2001) ressaltam que o que estava em jogo, dentre outras questões, era uma briga coorporativa pela exclusividade da atividade clínica, reivindicada por médicos e psicólogos.

Apesar da falta de regulamentação do ensino e da prática, ainda em 1953, inicia-se o primeiro curso superior autônomo de Psicologia, na Pontifícia Universidade Católica do Rio de Janeiro (Esch \& Jacó-Vilela, 2001; Yamamoto, 2006). No mesmo ano, a congregação da Faculdade de Filosofia, Ciências e Letras da Universidade de São Paulo (USP), a partir de proposta de Annita Cabral, aprova a criação do curso de Psicologia da instituição, embora este comece a funcionar efetivamente somente em 1958 (Rosas et al., 1988).

Em 1962, com a famosa Lei $n^{\circ} 4119$, finalmente a profissão e o curso de formação são oficialmente regulamentados. No mesmo ano, o Conselho Federal de Educação (CFE) emite o parecer no 403/62, fixando o currículo mínimo e a duração dos cursos de Psicologia. Esse documento compreende a formação em três níveis, cada qual com uma duração e um foco: bacharelado (4 anos), centrado na formação do pesquisador; licenciatura (4 anos), voltado para a formação do professor de Psicologia e formação do psicólogo (5 anos), dirigido à formação profissional. A seguir, em 1966, é criado, também na PUC/RJ, o primeiro curso de mestrado em Psicologia no Brasil (Yamamoto, 2006).

Com a regulamentação, assiste-se ao primeiro boom de abertura de cursos de Psicologia. Segundo Pereira e Pereira Neto (2003, p. 25), a década de 1970, em especial, "assinala um grande crescimento do número de profissionais formados em Psicologia. Esse incremento se explica pela proliferação dos cursos universitários particulares e também pelo aumento da demanda da população por serviços psicológicos". Bernardes (2004) afirma que o período que se estende de 1960 a 1979 é marcado pela enorme presença do Estado na sociedade, bem como pela desmobilização e pelo silêncio das entidades 
em Psicologia, o que, segundo ele, reforça o argumento defendido por Coimbra (1995) a respeito da relação entre essas entidades e a ditadura. "Esse é também o período identificado com o início da privatização do ensino, visto que o governo militar, por meio da Reforma Universitária (Lei $n^{\circ} 5.540 / 68$ ), apela ao setor privado para a resolução da chamada 'crise universitária'" (Bernardes, 2004). Nessa década, também são criados o Conselho Federal e os Conselhos Regionais de Psicologia, o primeiro Código de Ética Profissional, bem como o primeiro curso de doutorado em Psicologia no País, na USP (Pereira \& Pereira Neto, 2003).

No que diz respeito à formação, a década de 80 é analisada por Rocha Junior (1999) como um período de "certa calmaria e passividade, assistindo-se a pequenas mudanças, quase ajustes individuais de currículos sem qualquer expressão regional ou nacional" (p. 5). Bastos (2002 como citado por Souza, 2005) define os anos 80 como uma fase diagnóstica, no sentido de que os profissionais se interessaram em gerar dados e informações sobre o que acontecia na profissão e na formação. Fruto desse processo é a publicação do livro Quem é o Psicólogo Brasileiro? (Conselho Federal de Psicologia [CFP], 1988), primeiro grande diagnóstico da profissão e da formação do psicólogo no País.

Já a década de 90 se caracteriza por uma intensa mobilização das entidades profissionais, com destaque para o Conselho Federal e os Conselhos Regionais, no sentido de debater e concretizar mudanças relativas à formação. Logo em 1992, é organizado o I Encontro de Coordenadores de Curso de Formação de Psicólogos, que culminou com a Carta de Serra Negra, importante documento sobre a formação profissional do psicólogo brasileiro (Bernardes, 2004). Nesse mesmo ano e em 1994, são publicados, respectivamente, os importantes livros Psicólogo Brasileiro: Construção de Novos Espaços (Conselho Federal de Psicologia [CFP], 2005) e Psicólogo Brasileiro: Práticas Emergentes e Desafios para a Formação (Achcar, 1994).
Mais à frente, em 1996, com a promulgação da Lei de Diretrizes e Bases da Educação Nacional (LDB - Lei n ${ }^{\circ}$ 9.394/96), o Ministério da Educação (MEC) institui a Comissão de Especialistas em Ensino de Psicologia (Yamamoto, 2000). Essa comissão tinha como principal objetivo criar um projeto de diretrizes curriculares, em substituição ao antigo currículo mínimo. Em 1999, após três anos de debates com instituições de ensino superior e entidades profissionais, a Comissão apresenta uma minuta de resolução com as Diretrizes Curriculares para a Psicologia (Yamamoto, 2000). Grosso modo, a estrutura dessa minuta permanece na versão definitiva aprovada em 2004 através da Resolução n 8, de 12/05/2004 (Brasil, 2004b). Para Ferreira Neto (2004, p. 157), as Diretrizes configuram um avanço na medida em que "o currículo não é mais pensado a partir de conteúdos fundamentais que devem ser assimilados para posterior aplicação. A preocupação com conteúdos dá lugar a uma preocupação no desenvolvimento de competências e habilidades durante a formação".

Outro desdobramento da LDB é a avaliação nacional dos cursos de graduação, iniciada em 1996 com o Provão, formalmente denominado Exame Nacional de Cursos (ENC). Segundo Landeira-Fernandez e Primi (2002), somente em 2000 os cursos de graduação em Psicologia passaram a integrar esse sistema de avaliação. Witter e Ferreira (2005) informam ainda que tais cursos participaram do Provão nos anos 2000, 2001, 2002 e 2003, até que "em 2004, com o novo governo, houve mudanças no sistema, e a Psicologia ficou de fora da avaliação de 2004 e 2005. Nesse ano, começa uma nova sistemática, embora os aspectos fundamentais submetidos à avaliação permaneçam" (p. 22). Essa "nova sistemática", denominada Sistema Nacional de Avaliação da Educação Superior (SINAES), é implantada em 2004. Inserido no SINAES, o Exame Nacional de Desempenho dos Estudantes (ENADE) foi aplicado em 2006, em estudantes de 294 cursos de graduação de Psicologia, e teve seus resultados divulgados no ano seguinte. 
Ademais, outro marco da atualidade é a criação, em 1998, da Associação Brasileira de Ensino de Psicologia (ABEP), que, segundo Witter e Ferreira (2005, p. 21), é uma "entidade de âmbito nacional que tem a sua natureza institucional voltada para a reflexão, o desenvolvimento e o aprimoramento da formação em Psicologia no Brasil, buscando adequar a formação em Psicologia à realidade social do Brasil, à ética e ao exercício da cidadania". Desde sua criação, a ABEP tem encabeçado importantes discussões sobre diversos temas, dentre eles: educação à distância, reforma universitária, ensino de Psicologia no ensino médio e em outros cursos.

\section{Uma preocupação constante: a qualidade da formação do psicólogo}

Desde a década de 70, o tema da formação em Psicologia tem sido objeto de inúmeros estudos e debates. Estes comumente enfocam a questão curricular (Calais \& Pacheco, 2001; Dias, 2001; Matos, 2000; Medeiros, 1989; Mello, 1989), a formação científica ou formação para pesquisa (Matos, 1988; Natário, 1999; Pfromm Netto, 2007), a formação complementar e/ou extrauniversitária (Langenbach \& Negreiros, 1988), o estágio acadêmico (Witter et al., 2005), as metodologias de ensino e de supervisão (Bettoi \& Simão, 2002; Kodjaoglanian et al., 2003; Silva, 2004), a formação docente (Noronha, 2003) ou a relação entre graduação e pós-graduação (Gomes, 1996; Yamamoto, 2006). Além disso, questões éticas, políticas e epistemológicas, tais como aquelas representadas pelos dilemas formação técnica versus crítico-reflexiva, científica versus profissional, generalista versus especialista, predominantemente clínica versus pluralista, unidisciplinar versus multi/interdisciplinar, histórica versus contemporânea, elitista versus socialmente comprometida e voltada para indivíduos versus voltada para a coletividade, têm sido debatidas (Achcar, 1994; Bastos \& Bock, 1997; Duran, 1994; Ferreira Neto, 2004; Francisco \& Bastos, 2005; Gomide, 1988;
Gonçalves \& Bock, 1996; Martinez, 2003; Patto, 2005; Pereira, 1996; Pfromm Netto, 2007; Witter \& Ferreira, 2005; Yukimitsu, 1999). Mais recentemente, o impacto da avaliação nacional dos cursos de graduação (Landeira-Fernandez \& Primi, 2002; Primi, Landeira-Fernandez, \& Ziviani, 2003) e da implementação das chamadas novas diretrizes curriculares (Marinho-Araújo, 2007; Moura, 1999; Rocha Jr., 1999; Yamamoto, 2000) tem sido enfatizado.

O tema também tem sido intensamente explorado em interface com as diversas áreas de atuação do psicólogo, desde as chamadas áreas tradicionais, clínica (Ferreira Neto, 2004; Lo Bianco et al., 1994), organizacional (lema, 1999; Zanelli, 1994, 2002), escolar (Almeida, 2003; Campos, 2007; Maluf, 1994; Witter, 1999) e de avaliação psicológica (Noronha, 2002, 2006), até as chamadas áreas emergentes (Carvalho \& Sampaio, 1997), social-comunitária (Bomfim, 1994; Dimenstein, 1998), jurídica (Bomfim, 1994) e desportiva (Bomfim, 1994), dentre outras.

Um ponto em comum, contudo, parece nortear toda essa discussão: uma grande insatisfação no que tange à formação do psicólogo brasileiro. Esta é vista como extremamente deficitária tanto no que se refere à formação técnica quanto, e principalmente, à formação epistemológico-científica. Observase um enorme e crescente fosso entre o que é ensinado e aprendido em nossas instituições formativas e o que Pfromm Netto (2007, p. 10) chama de "estado atual da arte no contexto internacional", bem como uma significativa distância entre a formação acadêmica, a realidade profissional e as demandas da sociedade. Nesse sentido, Souza (2005, p. 46) afirma que a comunidade acadêmica freqüentemente defende, em contraposição ao atual modelo, uma formação "socialmente comprometida, reflexiva, ética, generalista, pluralista, interdisciplinar e que articule o compromisso social com as condições concretas postas pelo mercado". Porém, Witter e Ferreira (2005, p. 23) asseguram que, por melhor que seja o curso de graduação, 
"não é possível considerar que seja suficiente para formar bem o profissional para atuar em qualquer área", daí a crescente procura por cursos de pós-graduação.

Além disso, inúmeros autores (por exemplo, Gomes, 1996; Pfromm Netto, 2004; Rosas et al., 1988; Yamamoto, 2006) alertam para um excessivo, acelerado e desordenado aumento no número de cursos de Psicologia no País, o que geraria, como contrapartida, um sacrifício na qualidade dos mesmos. Assim, o presente estudo teve como objetivo caracterizar os cursos de graduação em Psicologia no Brasil.

\section{Método}

Para atingir o objetivo proposto, foram utilizados dados do Cadastro das Instituições de Ensino Superior do Ministério da Educação (MEC). Segundo a Portaria ${ }^{\circ} 1.885$, do MEC (Brasil, 2002b, p. 1), o Instituto Nacional de Estudos e Pesquisas Educacionais Anísio Teixeira (INEP) é o órgão gestor de tal cadastro, definido como um "sistema informatizado que permite à população acessar as informações relativas às instituições de educação superior vinculadas ao Sistema Federal de Ensino ou ao Sistema Estadual de Ensino". Seu conteúdo está disponível no site do INEP (www.inep.gov.br).

Um banco de dados foi formado incluindo as seguintes variáveis: nome da Instituição de Ensino Superior (IES), Município de funcionamento, Estado, Região, diploma conferido (bacharel, licenciado e/ou psicólogo), modalidade de ensino (presencial, semipresencial ou à distância), data de início do funcionamento do curso, prazo para integralização do curso, carga horária mínima do curso, regime letivo (semestral ou anual), turnos de oferta (matutino, vespertino, noturno e/ou integral), número de vagas autorizadas por turno (diurno e/ou noturno), organização acadêmica (universidade, faculdade, centro universitário, faculdades integradas ou instituto/ escola superior), categoria administrativa (pública ou privada) e avaliação do MEC nos anos 2000, 2001, 2002 e 2003 (ENC). Também foi incluída a variável Conceito Enade, retirada dos resultados do Exame Nacional de Desempenho dos Estudantes (ENADE), divulgados em 2007 e disponíveis também no site do INEP.

Com relação ao método, algumas considerações devem ser feitas: 1) os dados foram recolhidos entre setembro e novembro de 2007 ; 2) foram incluídos cinco cursos programados para começarem a funcionar no ano 2008; 3) com relação à variável diploma conferido, não foi possível chegar a um resultado propriamente dito em função de uma imprecisão no sistema cadastral do INEP, que realiza a contagem multiplicada dos cursos para cada uma das habilitações possíveis: bacharelado, licenciatura e formação do psicólogo. Dessa forma, cada curso consta no sistema como dois, três ou até quatro cursos diferentes, havendo um cadastro para cada habilitação, além de um cadastro geral. A metodologia utilizada no presente estudo considerou cada curso apenas uma vez.

Concluída a etapa de tabulação, empregaram-se estatísticas descritiva e inferencial para análise dos dados. Por omissão, no segundo caso, adotou-se um nível de significância de 0,05.

\section{Resultados e discussão}

Com relação ao número de cursos, foram identificados 396. A Tabela 1 apresenta a distribuição geográfica dos cursos por Estado e por Região. Verificou-se que a maioria deles se encontra na Região Sudeste $(\mathrm{n}=193$; $\left.48,74 \% ; \chi^{2}=234,5 ; g l=4 ; p=0,00\right)$, sendo o Estado de São Paulo sozinho responsável por $26,26 \%$ do total $\left(\mathrm{n}=104 ; \chi^{2} \mathrm{o}=810,9 ; \mathrm{gl}=\right.$ $26 ; p=0,00)$. Juntas, a Região Sul $(n=86$; $21,72 \%$ ) e a Sudeste acumulam $70,46 \%$ dos cursos. Já a Região Norte é a que apresenta a menor quantidade ( $n=27 ; 6,82 \%)$. Esses resultados convergem com a distribuição por Região apresentada por Witter e Ferreira (2005), embora o estudo dos autores tenha utilizado outro método. Quanto à distribuição por Estado, o presente estudo verificou outra disposição, estando em segundo lugar o Estado de Minas Gerais ( $n=47 ; 11,87 \%)$, e não o Rio de Janeiro $(n=31 ; 7,83 \%)$. 
Tabela 1. Distribuição geográfica dos cursos de graduação em Psicologia no Brasil.

\begin{tabular}{|c|c|c|c|}
\hline Região Geográfica/ & Unidade Federativa & $\mathrm{n}$ & $\%$ \\
\hline \multirow[t]{5}{*}{ Sudeste } & São Paulo & 104 & 26,26 \\
\hline & Minas Gerais & 47 & 11,87 \\
\hline & Rio de Janeiro & 31 & 7,83 \\
\hline & Espírito Santo & 11 & 2,78 \\
\hline & Total & 193 & 48,74 \\
\hline \multirow[t]{4}{*}{ Sul } & Rio Grande do Sul & 33 & 8,33 \\
\hline & Paraná & 27 & 6,82 \\
\hline & Santa Catarina & 26 & 6,57 \\
\hline & Total & 86 & 21,72 \\
\hline \multirow[t]{10}{*}{ Nordeste } & Bahia & 22 & 5,56 \\
\hline & Pernambuco & 12 & 3,03 \\
\hline & Ceará & 6 & 1,52 \\
\hline & Alagoas & 4 & 1,01 \\
\hline & Paraíba & 4 & 1,01 \\
\hline & Rio Grande do Norte & 4 & 1,01 \\
\hline & Piauí & 4 & 1,01 \\
\hline & Sergipe & 3 & 0,76 \\
\hline & Maranhão & 2 & 0,51 \\
\hline & Total & 61 & 15,40 \\
\hline \multirow[t]{5}{*}{ Centro-Oeste } & Goiás & 9 & 2,27 \\
\hline & Mato Grosso do Sul & 8 & 2,02 \\
\hline & Distrito Federal & 6 & 1,52 \\
\hline & Mato Grosso & 6 & 1,52 \\
\hline & Total & 29 & 7,32 \\
\hline \multirow{8}{*}{ Região Norte } & Amazonas & 8 & 2,020 \\
\hline & Rondônia & 7 & 1,77 \\
\hline & Pará & 3 & 0,76 \\
\hline & Amapá & 3 & 0,76 \\
\hline & Tocantins & 2 & 0,51 \\
\hline & Roraima & 2 & 0,51 \\
\hline & Acre & 2 & 0,51 \\
\hline & Total & 27 & 6,82 \\
\hline
\end{tabular}


Se for considerada população recenseada e estimada segundo as grandes Regiões do Brasil (Instituto Brasileiro de Geografia e Estatística [IBGE], 2007), verificar-se-á que as Regiões Sudeste e Sul têm, respectivamente, 42,33\% e 14,53\% dos habitantes do País. Contudo, a partir da Tabela 1, constatase que elas possuem, respectivamente, $48,74 \%$ e $21,72 \%$ dos cursos de graduação em Psicologia. Já a Região Nordeste, que concentra $28,00 \%$ da população brasileira, tem apenas $15,40 \%$ desses cursos. Há que se ressaltar que, no caso da pós-graduação em Psicologia, mais especificamente em mestrados e doutorados (Yamamoto \& Tourinho, 2006), a desigualdade regional é ainda mais evidente.

Algo semelhante ocorre quando são considerados os Estados. Para ilustrar, São Paulo, o Estado mais rico da Nação, possui sozinho $26,26 \%$ dos cursos de graduação em Psicologia, sendo que sua população perfaz 21,65\% dos habitantes do País.

Evidencia-se, assim, que as instituições superiores com cursos que propiciam formação inicial para psicólogos, predominantemente privadas - como será apresentado mais adiante - buscam as Regiões mais ricas da Federação para se instalarem. É mantida, dessa forma, a lógica de uma educação superior voltada para o mercado, e não necessariamente para as necessidades da população: busca-se o lucro onde o capital se concentra.

A maioria dos cursos de graduação em Psicologia do Brasil se localiza em cidades do interior do País ( $\mathrm{n}=246 ; 62,12 \%$; $\chi_{\mathrm{o}}^{2}=23,27 ; \mathrm{gl}=1 ; p=0,00$ ). Somente $150(37,88 \%)$ deles estão nas capitais. Mesmo quando são consideradas as regiões metropolitanas $^{1}$ ( $\mathrm{n}=178 ; 44,95 \%$ ), ainda assim prevalecem cursos localizados em cidades interioranas $(\mathrm{n}=218 ; 55,05 \%$; $\left.\chi_{\mathrm{a}}^{2}=4,04 ; \mathrm{gl}=1 ; p=0,04\right)$. Dessa forma, evidencia-se um estado de interiorização da formação em Psicologia não acompanhado de uma expansão geográfica para além da Região Sudeste.

Com relação à modalidade de ensino, verificase a exclusividade do ensino presencial nos cursos de graduação em Psicologia no Brasil. De acordo com documento elaborado pelo Grupo de Trabalho sobre Educação à Distância (GT-EaD) da Associação Brasileira de Ensino de Psicologia, existe a "possibilidade de cursos de Psicologia à distância começarem a ser credenciados", muito embora alguns já adotem disciplinas à distância e semi-presenciais (Associação Brasileira de Ensino de Psicologia, 2007, p. 1). Segundo esse documento, ainda que hoje não existam "cursos de graduação em Psicologia exclusivamente à distância, foi autorizado pelo MEC - através da Portaria no 4.059, de 10/12/2004 - que 20\% dos créditos dos cursos de graduação presenciais possam ser cumpridos em disciplinas semipresenciais" (p. 5). O GT afirma ainda que discutir tal possibilidade de ensino é necessário, em função da "enorme expansão que a EaD vem tendo, em decorrência do incentivo dado pelo Governo Federal", além de "suas perspectivas (reais ou especulativas) de aumentar o acesso à educação superior com baixo custo" (p. 1). Discussões à parte, o VI Congresso Nacional de Psicologia, realizado em julho de 2007, posicionou-se desfavoravelmente ao uso de EaD na formação inicial do psicólogo (ver alínea h da tese 62 - Conselho Federal de Psicologia, 2007).

No que se refere ao início do funcionamento do curso (Figura 1), verifica-se que, no período de 1958 a 2000, houve um incremento de 
188 cursos, número inferior aos 203 criados no intervalo entre 2001 e 2007. Assim, nesse pequeno período de seis anos, ocorreu a abertura da maioria dos cursos de Psicologia do País ( $n=203 ; 51,26 \% ; \chi^{2}=537,68$; $\mathrm{gl}=6 ; p=0,00$ ), o que configura um aumento de mais de $200 \%$. Juntas, a década de 90 e a presente década, até o ano 2007, acumulam cerca de $74 \%$ do total de cursos criados. Trata-se, realmente, de uma enorme e rápida expansão. Segundo Catani e Oliveira (2002, p. 13), esse crescimento acontece de forma desordenada, uma vez que "a) se concentra na rede privada; $b$ ) se dá por meio da abertura de vagas em cursos relativamente baratos; c) ocorre nos cursos, nas cidades e Regiões onde já há maior oferta de vagas; d) está implicando perda da qualidade do ensino superior".

Pode-se verificar ainda três momentos de grande crescimento do número de cursos: o primeiro na década de 70 , o segundo na década de 90, e o terceiro, nesta primeira década do século XXI. Em cada um desses momentos, um ano se destaca: no primeiro, 1972, no segundo, 1997, e, no terceiro, 2006.

O primeiro boom, como já visto, parece estar relacionado, dentre outros fatores, à Reforma Universitária realizada em 1968. Segundo Martins (1981, como citado por lema, 1999, p. 32), essa reforma "previa a não criação de novas faculdades onde as profissões estivessem adequadamente atendidas, a não ser em casos excepcionais de cursos que apresentassem alto padrão". Mas, de fato, o que ocorreu "foi a aprovação de uma enorme quantidade de cursos, principalmente na área de ciências humanas e Letras" (p. 32). De acordo com Freitag (1980, como citado por lema, 1999, p. 32), tais cursos "podem tranqüilamente funcionar à noite, porque exigem poucas instalações e têm à disposição recursos humanos de fácil recrutamento". Enfim, um curso de Psicologia, quando comparado a outros, é "relativamente barato na sua estruturação e com um retorno financeiro efetivo a curto prazo. Além disso, torna-se mais barato ainda, dadas as condições inadequadas nas quais a maioria dos cursos se encontra" (Holanda, 1997)

Com relação ao segundo boom (1997), verifica-se uma importante relação com a promulgação da nova LDB (Brasil, 1996). Segundo Yamamoto (2006, p. 30), a LDB sancionada "expressa uma estreita sintonia com o ideário e a agenda neoliberais", o que se traduz, na prática, em ações de cunho mercadológico que privilegiam a quantidade em vez da qualidade do ensino. Nesse sentido, de acordo com Gomes (1996, p. 40), é preciso destacar que "a rápida expansão dos cursos de Psicologia não esperou pelos professores qualificados. A falta de qualificação docente transformou o nosso problemático currículo em um elenco imprestável de artificialidades. As peças não se completavam, não constituíam um todo".

Já o crescimento vertiginoso de 2006, que configura o terceiro boom, parece estar relacionado a diversos fatores, inclusive à promulgação da LDB quase 10 anos antes (Brasil, 1996). Além disso, segundo Ferreira Neto (2004, p. 161), "o que temos em curso no ensino superior é uma definição política em favor da soberania do mercado como gestor maior dos serviços do setor". A ponderação anterior é corroborada ao se constatar que a maioria dos cursos abertos em 2006 pertence a instituições privadas $\left(\mathrm{n}=39 ; 84,78 \% ; \chi^{2}=22,26 ; \mathrm{gl}=1 ; p\right.$ $=0,00)$. 


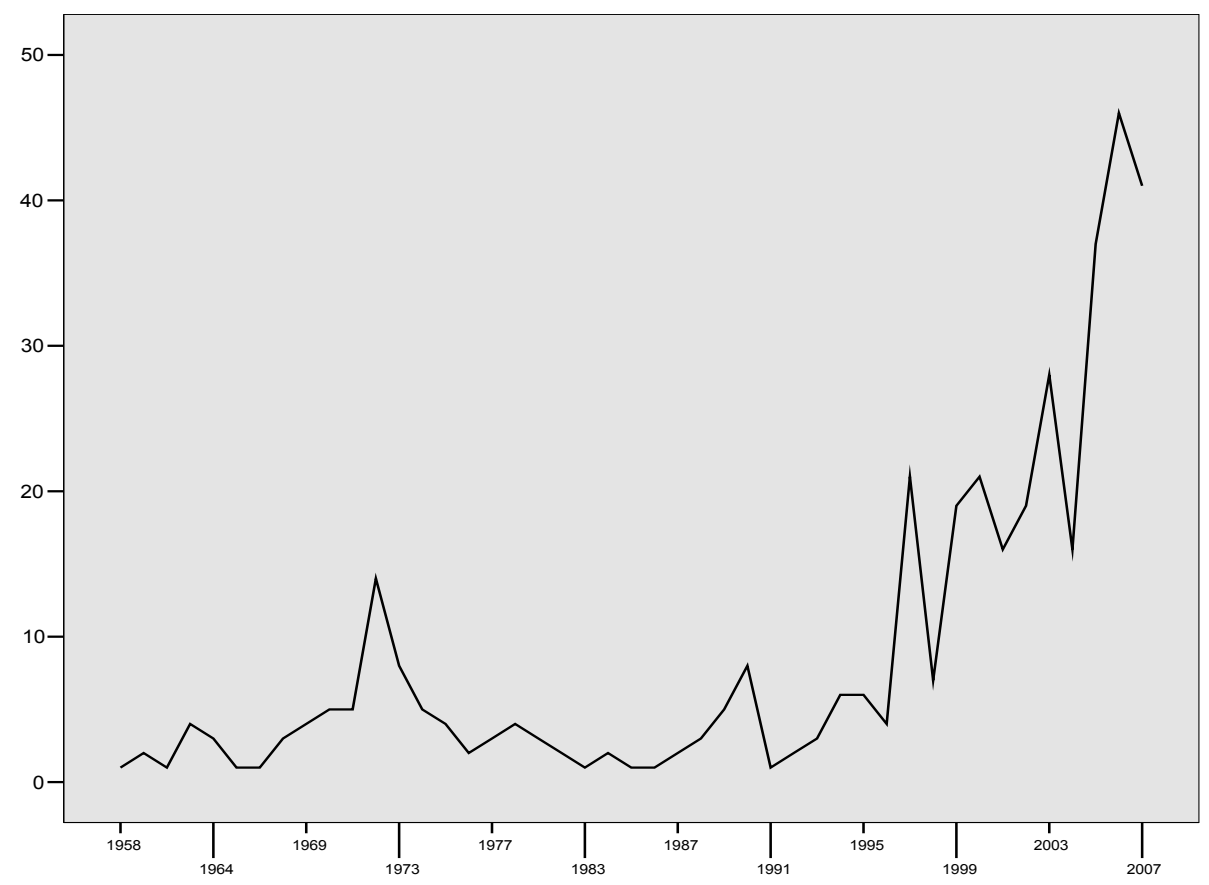

Ano de Início

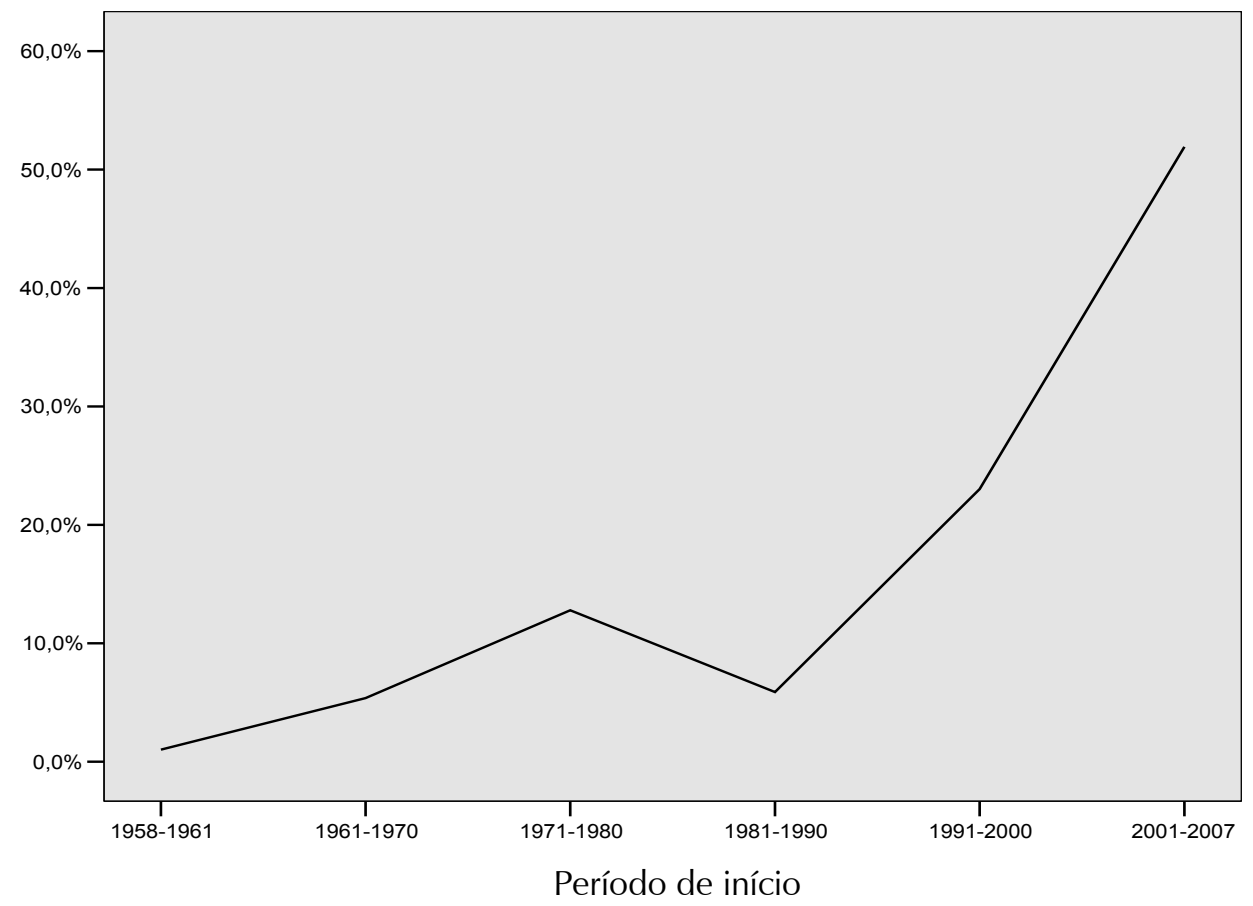

Figura 1. Período e ano de início do funcionamento dos cursos de graduação em Psicologia no Brasil.

Com relação ao prazo esperado para integralização (Tabela 2), predomina o período de 10 semestres ou 5 anos $\left(\mathrm{n}=292 ; 74,49 \%, \chi_{\varrho}^{2}=1663,71 ; \mathrm{gl}=8 ; p=0,00\right)$. Abaixo desse patamar, encontram-se 82 cursos (20,92\%), e acima, 18 (4,59\%), sendo que o menor prazo encontrado foi de 4 semestres ( 2 anos), referente a um curso de licenciatura em Minas Gerais, e o maior de 14 (7 anos), relativo a quatro cursos, um da Região Sul e os demais da Sudeste. 
Tabela 2. Características gerais dos cursos de graduação em Psicologia no Brasil.

\begin{tabular}{|c|c|c|c|}
\hline & Variáveis & $\mathrm{n}$ & $\%$ \\
\hline \multirow{10}{*}{$\begin{array}{l}\text { Prazo para integralização } \\
\text { do curso - Semestres }\end{array}$} & 10 & 292 & 74,49 \\
\hline & 8 & 63 & 16,07 \\
\hline & 9 & 13 & 3,32 \\
\hline & 11 & 9 & 2,30 \\
\hline & 12 & 5 & 1,28 \\
\hline & 14 & 4 & 1,02 \\
\hline & 7 & 3 & 0,77 \\
\hline & 6 & 2 & 0,51 \\
\hline & 4 & 1 & 0,26 \\
\hline & Total & 392 & 100 \\
\hline \multirow[t]{3}{*}{ Regime Letivo } & Semestral & 353 & 90,51 \\
\hline & Anual & 37 & 9,49 \\
\hline & Total & 390 & 100 \\
\hline \multirow[t]{9}{*}{ Turnos de oferta } & Matutino e Noturno & 157 & 39,65 \\
\hline & Noturno & 81 & 20,45 \\
\hline & Integral & 59 & 14,90 \\
\hline & Matutino & 37 & 9,34 \\
\hline & Vespertino e Noturno & 19 & 4,80 \\
\hline & Todos & 18 & 4,55 \\
\hline & Matutino e Vespertino & 17 & 4,29 \\
\hline & Vespertino & 8 & 2,02 \\
\hline & Total & 396 & 100 \\
\hline \multirow[t]{6}{*}{ Organização Acadêmica } & Universidade & 200 & 50,51 \\
\hline & Faculdade & 114 & 28,79 \\
\hline & Centro Universitário & 51 & 12,88 \\
\hline & Faculdades integradas & 16 & 4,04 \\
\hline & Instituto Superior ou Escola Superior & 15 & 3,79 \\
\hline & Total & 396 & 100 \\
\hline \multirow[t]{3}{*}{ Categoria Administrativa - Síntese } & Privada & 334 & 84,34 \\
\hline & Pública & 62 & 15,66 \\
\hline & Total & 396 & 100 \\
\hline \multirow[t]{11}{*}{ Categoria Administrativa } & Privada - Particular em sentido estrito & 211 & 53,28 \\
\hline & Privada - Filantrópica & 48 & 12,12 \\
\hline & Pública Federal & 37 & 9,34 \\
\hline & Privada - Comunitária - Confessional - Filantrópica & 21 & 5,30 \\
\hline & Privada - Confessional - Filantrópica & 19 & 4,80 \\
\hline & Privada - Comunitária & 17 & 4,29 \\
\hline & Pública Municipal & 13 & 3,28 \\
\hline & Pública Estadual & 12 & 3,03 \\
\hline & Privada - Com unitária - Filantrópica & 11 & 2,78 \\
\hline & Privada - Confessional & 7 & 1,77 \\
\hline & Total & 396 & 100 \\
\hline
\end{tabular}


Quanto à carga horária mínima do curso, a média em horas encontrada foi de $4.042,21 \pm 515,21$, sendo o valor mínimo de 580 horas, referente ao curso de licenciatura já citado, e o máximo de 5960 horas, referente a um curso da Região Nordeste. Segundo a Resolução n 2, de junho de 2007, do Ministério da Educação (Brasil, 2007a), a carga horária mínima estabelecida para os cursos de Psicologia é de 4.000 horas. Embora a maioria dos cursos identificados esteja adequado a esse piso $(\mathrm{n}=293$; $\left.74,00 \%, \chi_{o}^{2}=96,01 ; \mathrm{gl}=1 ; p=0,00\right)$, uma parcela considerável $(n=99 ; 26,00 \%)$ encontra-se abaixo desse mínimo indicado. Segundo essa mesma Resolução, os estágios e atividades complementares não podem exceder $20 \%$ da carga horária total do curso, ou seja, não podem ultrapassar 800 horas. Além disso, a Resolução estabelece que, para os cursos incluídos no Grupo de Carga Horária Mínima entre 3600 e 4000 horas, dentre eles a Psicologia, o limite mínimo para integralização deverá ser de cinco anos (Brasil, 2007a). Isso significa que, até o prazo estabelecido pela Resolução, todos os cursos de Psicologia do País deverão se ajustar a essa norma.

Em consonância com essa Resolução, as Diretrizes Curriculares da Psicologia aboliram a divisão da formação em três habilitações. Adotou-se uma terminalidade única, isto é, a de psicólogo (Brasil, 2004a). Segundo texto disponível no site da Associação Brasileira de Ensino de Psicologia (Associação Brasileira de Ensino de Psicologia, 2005), essa formação corresponde ao que em outros cursos é chamado de bacharelado. Não à toa, todos os cursos programados para iniciarem suas atividades em 2008 apresentam como único diploma a ser conferido o de bacharel. Isso não significa mais uma formação específica para o pesquisador em Psicologia, mas a formação de um psicólogo necessariamente pesquisador. A formação em licenciatura segue, agora, outras diretrizes, no caso aquelas instituídas pela Resolução CNE/CP $n^{\circ} 1$, de 15/05/2006 (Brasil, 2006), bem como diferentes duração - 3 anos - e carga horária - 2.800 horas (Brasil, 2002a). De qualquer forma, o prazo para adequação a essas novas regras (maio de 2006, segundo a Associação Brasileira de Ensino de Psicologia, 2005, e Brasil, 2004c) já passou, e muitos cursos ainda mantêm velhos padrões.

Com relação ao regime letivo (Tabela 2), evidencia-se a adoção, pela maior parte dos cursos, do regime semestral $(\mathrm{n}=353$; $\left.90,51 \% ; \chi_{\circ}^{2}=256,04 ; \mathrm{gl}=1 ; p=0,00\right) \mathrm{em}$ vez do regime anual $(n=37 ; 9,49 \%)$. Esse fato pode apontar um certo tradicionalismo no ensino da Psicologia. Outras possibilidades pedagógicas/metodológicas, como o regime seriado, por sistema de crédito ou por módulos acadêmicos, não têm sido consideradas pelas instituições. Ferramentas pedagógicas, como o Estudo Baseado em Problemas - PBL (Problem Based Learning), (ver, por exemplo, Kodjaoglanian et al., 2003) acabam por não se impor frente à organização temporal tradicional. De acordo com a Associação Brasileira de Ensino de Psicologia (2005), existe uma "ampla gama de possibilidades de se estruturar a formação, diversificando os espaços de aprendizagem, criando mecanismos de integração e ampliando a interação que desenvolva habilidades e competências transversais". No entanto, para que essas possibilidades se tornem realidade, é necessário um trabalho coletivo que envolva a "ruptura com o modelo tradicional e dominante de se fazer reformas curriculares - restritas ao re-arranjo de disciplinas" (Associação Brasileira de Ensino de Psicologia, 2005).

No que se refere aos turnos de oferta (Tabela 2), verifica-se que a maioria dos cursos funciona em turnos parciais (n $=337 ; 85,10 \% ; \chi^{2}{ }_{o}=195,16 ; \mathrm{gl}=1 p$ $=0,00)$. Assim, constata-se que $275(69,44 \%)$ oferecem vagas no período noturno, 229 
$(57,82 \%)$, no matutino, e $62(15,66 \%)$, no vespertino. Apenas 59 cursos (14,89\%) oferecem turno integral. A organização de turnos mais adotada é o "matutino e noturno" ( $\mathrm{n}=157 ; 39,65 \% ; \chi_{\mathrm{o}}^{2}=353,4$; $\mathrm{gl}=7 ; p=0,00)$. É importante ressaltar que cada turno corresponde a pelo menos uma turma diferente.

Se considerados fora de contexto, os resultados descritos no parágrafo anterior parecem revelar uma diferença não tão significativa no que se refere ao oferecimento dos cursos no período noturno e matutino. Contudo, é sabido que a formação inicial do psicólogo brasileiro ocorre predominantemente à noite. O que os resultados não permitem vislumbrar é o fato de que muitos cursos, apesar de abrirem vagas (algumas vezes muitas vagas) no período matutino, acabam por não preenchê-las, mantendo uma quantidade muito menor de estudantes matriculados nesse turno.

Com relação às vagas autorizadas por turno (diurno ou noturno, segundo o cadastro do INEP), verifica-se o predomínio do período noturno, quando são abertas 28.325 vagas ( $\left.\bar{X}=107,05 \pm 87,4 ; Z_{o}=-2,68 ; p=0,01\right)$. Somadas às 27.200 do período diurno ( $\bar{X}=98,07 \pm 83,5)$, totaliza-se cerca de 55.445 vagas $(\bar{X}=146,29 \pm 136,27)$ abertas para os cursos de Psicologia no País, sendo que somente o Estado de São Paulo é responsável por 22.862 destas (41,23\%). Não foi possível identificar, pelos dados do INEP, a periodicidade de abertura dessas vagas, isto é, se elas são abertas anualmente ou semestralmente. Poder-se-ia inferir que cursos de regime letivo anual abrem vagas anualmente, e o mesmo ocorreria com os semestrais, mas é sabido que há cursos semestrais com entrada anual e vice-versa.

No tocante à organização acadêmica (Tabela 2), verifica-se a prevalência das instituições universitárias $\left(\mathrm{n}=200 ; 50,5 \% ; \chi_{\mathrm{o}}^{2}=312,05\right.$; $\mathrm{gl}=4 ; p=0,00)$ no oferecimento de cursos de graduação em Psicologia no Brasil. As faculdades isoladas configuram apenas $28,79 \%(n=114)$, e as demais organizações, juntas, constituem cerca de $20 \%$ do total (n = 82). Segundo lema (1999, p. 32), com a Reforma Universitária de 1968, “o ensino deveria ser ministrado nas universidades e só excepcionalmente em escolas isoladas, para que pudesse estar mais vinculado à pesquisa". Porém, de acordo com Freitag (1980, como citado por lema, 1999, p. 32), "o que deveria ser exceção virou regra, e o número de faculdades isoladas cresceu mais que os cursos criados nas universidades". O quadro parece ter se modificado, muito embora o número de faculdades isoladas cresça a cada ano, especialmente a partir de 1999.

Com relação à categoria administrativa, constata-se que a maioria absoluta dos cursos se localiza em instituições privadas ( $\mathrm{n}=334$; $84,34 \% ; \chi_{\varrho}^{2}=186,82 ; \mathrm{gl}=1 ; p=0,00$ ). As públicas constituem apenas $15,66 \%$ do total $(n=62)$. A Tabela 2 apresenta uma especificação desses resultados. Verifica-se que, entre as instituições privadas, prevalecem as "particulares em sentido estrito", isto é, aquelas com fins lucrativos $(\mathrm{n}=211$; $\left.63,2 \% ; \chi_{o}^{2}=673,79 ; \mathrm{gl}=6 ; p=0,00\right), \mathrm{e}$, entre as instituições públicas, predominam as federais $\left(\mathrm{n}=37 ; 59,7 \% ; \chi_{\mathrm{o}}^{2}=19,38 ; \mathrm{gl}=2\right.$; $p=0,00)$.

Um termo muito utilizado para se referir às políticas educacionais modernas é a "mercantilização do ensino". Decorrente desse processo, está o problema da qualificação docente. De acordo com Yamamoto (2006), enquanto 91,7\% das instituições públicas atendem à exigência de $1 / 3$ de docentes titulados, somente $24,4 \%$ das privadas o fazem. E dificilmente o farão nos próximos anos, haja vista que, em 2005, havia 230.734 docentes no ensino superior no Brasil, sendo que, destes, apenas 22,7\% eram doutores e 35\% mestres (Yamamoto, 2006). 
Verifica-se, dessa forma, um significativo déficit na qualificação docente. Segundo o autor, intervir nessa questão é o grande objetivo do sistema de pós-graduação.

Outro problema decorrente dessa mercantilização da educação superior brasileira é a carência de atividade de pesquisa nas instituições privadas. Segundo dados do Governo Federal (Brasil, 2007b, p. 6), nos últimos anos, "a comunidade científica do País produziu 1,92\% dos trabalhos científicos publicados no mundo inteiro, ao mesmo tempo em que 93\% dos programas de pós-graduação estão concentrados em universidades públicas, responsáveis por $97 \%$ da produção científica do País". Para Mello (1989, p. 18), "o problema não começa com o fato de o aluno não fazer pesquisa, mas de o professor não ser também um pesquisador".

Quanto às avaliações dos cursos (Tabela 3), verifica-se uma predominância do conceito médio (C ou 3) em todas elas: ENC 2000 $\left(\mathrm{n}=45 ; 37,19 \% ; \chi^{2}=29,95 ; \mathrm{gl}=4\right.$; $p=0,00)$; ENC 2001 ( $\mathrm{n}=79 ; 61,72 \%$; $\left.\chi_{\mathrm{o}}^{2}=141,14 ; \mathrm{gl}=4 ; p=0,00\right) ; \mathrm{ENC} 2002$ $\left(\mathrm{n}=93 ; 65,96 \% ; \chi_{\mathrm{o}}^{2}=189,10 ; \mathrm{gl}=4\right.$; $p=0,00) ;$ ENC 2003 ( $\mathrm{n}=96 ; 60,76 \%$; $\left.\chi_{\circ}^{2}=168,13 ; \mathrm{gl}=4 ; p=0,00\right)$; e ENADE $2006\left(\mathrm{n}=126 ; 40,51 \% ; \chi^{2}=222,61 ; g \mathrm{l}=5\right.$; $p=0,00)$. Ao considerar somente os cursos que passaram pelas cinco avaliações aqui consideradas ( $\mathrm{n}=108$ ), constatou-se uma diferença significativa entre elas $\left(\chi_{\mathrm{o}}^{2}=19,88\right.$; $\mathrm{gl}=4 ; p=0,00)$, sendo observada uma tendência de o desempenho melhorar ao longo do tempo. O ano 2002 foi exceção nesse processo, pois, ao compará-lo com 2001, verifica-se um retrocesso. Contudo, mesmo assim, os resultados foram melhores que em 2000.
Tabela 3. Resultados das avaliações nacionais dos cursos de graduação em Psicologia no Brasil.

\begin{tabular}{|c|c|c|c|}
\hline ENC 2000 & A & 15 & 12,40 \\
\hline & B & 21 & 17,36 \\
\hline & C & 45 & 37,19 \\
\hline & $\mathrm{D}$ & 29 & 23,97 \\
\hline & E & 11 & 9,09 \\
\hline & Total & 21 & 100 \\
\hline \multirow[t]{6}{*}{ ENC 2001} & A & 14 & 10,94 \\
\hline & B & 17 & 13,28 \\
\hline & $\mathrm{C}$ & 79 & 61,72 \\
\hline & $\mathrm{D}$ & 10 & 7,81 \\
\hline & $\mathrm{E}$ & 8 & 6,25 \\
\hline & Total & 28 & 100 \\
\hline \multirow[t]{6}{*}{ ENC 2002} & A & 13 & 9,22 \\
\hline & B & 19 & 13,48 \\
\hline & $\mathrm{C}$ & 93 & 65,96 \\
\hline & $\mathrm{D}$ & 7 & 4,96 \\
\hline & $E$ & 9 & 6,38 \\
\hline & Total & 41 & 100 \\
\hline \multirow[t]{6}{*}{ ENC 2003} & A & 17 & 10,76 \\
\hline & B & 24 & 15,19 \\
\hline & $\mathrm{C}$ & 96 & 60,76 \\
\hline & $\mathrm{D}$ & 9 & 5,70 \\
\hline & $E$ & 12 & 7,59 \\
\hline & Total & 58 & 100 \\
\hline \multirow[t]{7}{*}{ ENADE 2006} & 1 & 7 & 2,25 \\
\hline & 2 & 22 & 7,07 \\
\hline & 3 & 26 & 40,51 \\
\hline & 4 & 60 & 19,29 \\
\hline & 5 & 9 & 2,89 \\
\hline & Sem conceito & 87 & 27,97 \\
\hline & Total & 11 & 100 \\
\hline
\end{tabular}


O resultado descrito no parágrafo anterior pode, em primeira análise, parecer alentador. Todavia, ele deve ser considerado com muita cautela, já que a totalidade dos cursos de graduação da área não é considerada. $\mathrm{Na}$ verdade, somente uma minoria dos cursos ( $\mathrm{n}=108)$ passou por todas as avaliações $\left(\chi_{o}^{2}=81,82 ; g l=1 ; p=0,00\right)$. Destacase, ainda, que persiste entre docentes e discentes a sensação de que a qualidade da formação inicial dos psicólogos brasileiros está muito distante da necessária para exercer a profissão, talvez porque ser psicólogo no Brasil e para o Brasil demande muito mais que uma qualificação mediana.

Para Yamamoto (2006), embora existam muitos questionamentos pertinentes com relação aos resultados do Provão - e até mesmo do Enade -, não deixa de ser preocupante esse caráter mediano da formação em Psicologia no Brasil. Constatase, contudo, que as instituições públicas são sistematicamente melhor avaliadas que as instituições privadas. Para exemplificar, nenhum curso vinculado a uma instituição privada tirou o conceito máximo (5) no Enade. Apenas nove cursos (2,89\%) o fizeram, todos inseridos em instituições públicas. Da mesma forma, verifica-se que apenas 15,38\% $(\mathrm{n}=8)$ dos cursos públicos tiraram o conceito médio (3), enquanto $45,56 \%(n=118)$ dos privados o fizeram.

\section{Conclusão}

A partir de alguns estudos (Achcar, 1994; Conselho Federal de Psicologia [CFP], 1988; Organização Mundial de Saúde/Conselho Federal de Psicologia [OMS/CFP], 2001), é possível traçar um perfil do psicólogo brasileiro: ele é do sexo feminino, é jovem, atua predominantemente na área clínica e tem baixa remuneração. Ao realizar a presente investigação, constatou-se que, além disso, o psicólogo brasileiro é formado em um curso de graduação presencial de uma universidade privada com fins lucrativos localizada no interior do País, principalmente da Região Sudeste. Além disso, esse curso funciona em turnos parciais, geralmente à noite, abre muitas vagas no processo seletivo, tem duração de 10 semestres, carga-horária média de aproximadamente 4.000 horas e, nas avaliações nacionais, obtém o conceito médio.

Em uma publicação sobre Política Educacional e Formação Profissional do Psicólogo (Saviani et al., 1984), o Conselho Federal de Psicologia apresenta trechos de entrevistas com profissionais de grande relevância para o tema. Dentre eles, está Isaías Pessoti, que, em entrevista, ponderou que a formação dos primeiros psicólogos brasileiros "foi viezada. Não se fazia o pretendido, o desejado..." (p. 30). Mais de uma década após a publicação desse texto e cinco do início dos cursos de graduação em Psicologia, os resultados da presente investigação permitem parafrasear Pessoti para afirmar que a formação ofertada atualmente para os estudantes de graduação em Psicologia não é a pretendida, a desejada.

Não obstante as limitações do presente estudo, especialmente aquelas relacionadas às fontes dos dados, que podem gerar resultados específicos enviesados, o panorama geral por ele identificado parece refletir com bastante proximidade o quadro global dos cursos de graduação em Psicologia no Brasil. Isso permite tecer algumas considerações sobre três transformações que, para os autores, devem ser operadas urgentemente para que, no futuro, a formação inicial dos psicólogos seja a pretendida, a desejada:

- Em primeiro lugar, é urgente romper a lógica de mercado que determina a distribuição, a organização e o funcionamento dos cursos de graduação em Psicologia brasileiros. Fernandes (2001) denuncia a "ênfase privativista" e a "inclinação para dar respostas mais de acordo com o mercado de trabalho" que assola as instituições de educação superior nacionais e internacionais. Ferreira Neto (2004) também critica o caráter ditatorial que as normas de mercado assumiram na formação universitária. Além disso, tece críticas ao tecnicismo que tem inundado as instituições de formação profissional.

- A segunda transformação desejada e imprescindível, diretamente relacionada à primeira, diz respeito à necessidade de fortalecer a universidade pública e torná-la o principal lócus da formação dos psicólogos brasileiros. Instituições de educação superior 
verdadeiramente públicas constituem uma alternativa viável e necessária para combater o que Guzzo (2007) denominou "educação como mercadoria, e não como direito". "O mal-estar democrático no qual vivemos, para além da má distribuição de riquezas, deve se à decadência e ao abandono das instituições públicas..." (Fernandes, 2001).

- Não se ensina adequadamente na maioria dos cursos de graduação em Psicologia; não se avalia efetivamente o futuro profissional. Assim, como terceira consideração decorrente do presente estudo, tem-se a necessidade de mudar radicalmente o modo como se ensina nos cursos de graduação da área, mais especificamente o currículo e sua organização, bem como a forma como se avalia a formação dos psicólogos. A formação inicial ofertada atualmente aos futuros profissionais se mostra totalmente alheia às novas formas de organização curricular, tais como a aprendizagem baseada em problemas (ver, por exemplo, Kodjaoglanian et al., 2003). Ela está presa a um passado que, no passado, já era insatisfatório, como analisou Pessoti (Saviani et al., 1984). É preciso formar psicólogos para a excelência, para o pleno exercício de seus papéis sociais, e não profissionais medianos, treinados para obter a média no Provão, que apresenta problemas devidamente analisados por Primi, Landeira-Fernandez e Ziviani (2003). Fernandes (2001) recomenda que, tendo como base as diretrizes curriculares para os cursos, essa avaliação trilhe "outro caminho, numa perspectiva que seja processual, contínua, e que tenha como meta principal a melhoria da qualidade da formação". ..."Cumpre desenvolver um modelo de avaliação que tenha o foco não apenas nos resultados aferidos a partir dos egressos dos cursos, mas que considere, sobretudo, o processo de formação, que supõe apoio noutros princípios".

Após 45 anos de regulamentação no Brasil, a Psicologia chegou a um patamar possivelmente inimaginável para os pioneiros. Há que se reconhecer que o passado permitiu que muitas conquistas se efetivassem e que somente conhecendo-o é possível entender o presente, libertar-se dos fantasmas e planejar o futuro. Os atuais cursos de graduação na área, espectros dessa história, muito se assemelham ao protótipo estabelecido pelos primórdios, não atendem as demandas atuais e não capacitam os profissionais para serem os agentes de transformação que o País tanto precisa. A formação inicial dos psicólogos brasileiros não é a pretendida, a desejada pelos próprios integrantes da área e, também, por aqueles que dela podem se beneficiar. Forma-se, atualmente, para o passado, para poucos, para a manutenção, para a alienação. Há que se formar para o futuro, para o compromisso social, para a transformação, para a libertação.

\section{Felipe Stephan Lisboa*}

Bacharel em Psicologia pela Universidade Federal de Juiz de Fora e Psicólogo da Universidade Federal de Viçosa, Viçosa, MG - Brasil.

\section{Altemir José Gonçalves Barbosa}

Professor do Programa de Pós-Graduação em Psicologia e do Curso de Graduação do Departamento de Psicologia da Universidade Federal de Juiz de Fora, Juiz de Fora, MG - Brasil.

E-mail: altgonc@uol.com.br

*Endereço para envio de correspondência:

Av. Rio Branco n 3845, ap. 301B, Centro, Juiz de Fora, MG - Brasil - CEP: 36010-011

E-mail: felipsi_ufjf@yahoo.com.br

Recebido 20/08/2008, Reformulado 16/02/2009, Aprovado 26/02/2009 


\section{Referências}

Achcar, R. (Org.) . (1994). Psicólogo brasileiro: práticas emergentes e desafios para a formação. São Paulo: Casa do Psicólogo.

Almeida, J. F. C. (Org.). (2003). Psicologia escolar, ética e competência na formação e atuação profissional. Campinas, SP: Alínea.

Antunes, M. A. M. (2003). A psicologia no Brasil: leitura histórica sobre sua constituição. São Paulo: Unimarco; Educ.

Associação Brasileira de Ensino de Psicologia. (2005). Construção de acordos sobre a aplicação das Diretrizes Curriculares para os cursos de psicologia no país. Recuperado em 30 de novembro de 2007, de www.abepsi.org.br

Associação Brasileira de Ensino de Psicologia. (2007). Grupo de trabalho sobre educação à distância da ABEP: texto preliminar e plano de trabalho. Recuperado em 30 de novembro de 2008, www.abepsi.org.br/abep/educacao_distancia.aspx

Bastos, A. V. B., Achcar, R. (1994). Dinâmica profissional e formação do psicólogo: uma perspectiva de integração. In Conselho Federal de Psicologia, Psicólogo brasileiro: práticas emergentes e desafios para a formação (pp. 245-271). São Paulo: Casa do Psicólogo.

Bernardes, J. S. (2004). O debate atual sobre a formação em psicologia no Brasil: análise de documentos de domínio público. Estudos e Pesquisas em Psicologia, 3(2), 2004. Disponível em: www.revispsi.uerj.br

Bettoi, W., \& Simão, L. M. (2002). Entrevista com profissionais como atividade ensino-aprendizagem desejável na formação do psicólogo. Psicologia: Reflexão e Crítica, 15(3), 613-624.

Bock, A. M. B. (1997). Formação do psicólogo: um debate a partir do significado do fenômeno psicológico. Psicologia: Ciência e Profissão, 17(2), 37-42.

Bomfim, E. M. (1994). Psicologia social, psicologia do esporte, psicologia jurídica. In Conselho Federal de Psicologia, Psicólogo brasileiro: práticas emergentes e desafios para a formação (pp. 201-243). São Paulo: Casa do Psicólogo.

Brasil. (1996). Lei $n^{\circ}$ 9.394, de 20 de dezembro. Estabelece as Diretrizes e Bases da Educação Nacional. Brasília, DF: Ministério da Educação/Conselho Nacional de Educação/Câmara de Educação Superior.

Brasil. (2002a). Resolução CNE/CPn ${ }^{\circ}$ 2, de 19 de fevereiro. Institui a duração e a carga horária dos cursos de licenciatura, de graduação plena, de formação de professores da educação básica em nível superior. Brasília, DF: Ministério da Educação/Conselho Nacional de Educação/Conselho Pleno.

Brasil. (2002b). Portaria $n^{\circ} 1.885$, de 27 de junho. Institui o cadastro das instituições de ensino superior. Brasília, DF: Ministério da Educação/Gabinete do Ministro.

Brasil. (2004a). Parecer CNE/CES n 0062, de 19 de fevereiro. Dispõe sobre as Diretrizes Curriculares Nacionais para os Cursos de graduação em psicologia. Brasília, DF: Ministério da Educação/ Conselho Nacional de Educação/Câmara de Educação Superior.

Brasil. (2004b). Resolução $n^{\circ}$ 8, de 7 de maio. Institui as Diretrizes Curriculares Nacionais para os cursos de graduação em Psicologia. Brasília, DF: Ministério da Educação/Conselho Nacional de Educação/ Câmara de Educação Superior.

Brasil. (2004c). Parecer CNE/CES n 210, de 08 de julho. Aprecia a Indicação CNE/CES no 1/2004, referente à adequação técnica e revisão dos pareceres e/ou resoluções das Diretrizes Curriculares Nacionais dos cursos de graduação. Brasília, DF: Ministério da Educação/Conselho Nacional de Educação/Câmara de Educação Superior.

Brasil. (2006). Resolução CNE/CP $n^{\circ} 1$, de 15 de maio. Institui Diretrizes Curriculares Nacionais para o curso de graduação em pedagogia, licenciatura. Brasília: Ministério da Educação/ Conselho Nacional de Educação/Conselho Pleno.

Brasil. (2007a). Resolução $n^{\circ}$ 2, de 18 de junho. Dispõe sobre carga horária mínima e procedimentos relativos à integralizacão e duração dos cursos de graduação, bacharelados, na modalidade presencial. Brasília, DF: Ministério da Educação/Conselho Nacional de Educação/Câmara de Educação Superior.

Brasil. (2007b). Reestruturação e expansão das universidades federais - REUNI: diretrizes gerais. Brasilia, DF: Ministério da Educação.

Cabral, A. C. M. (2004). A psicologia no Brasil (1950). In M. A. M. Antunes (Org.), História da psicologia no Brasil: primeiros ensaios (pp. 33-70). Rio de Janeiro: EdUERJ; Brasília, DF: Conselho Federal de Psicologia.
Calais, S. L., \& Pacheco, E. M. C. (2001). Formação de psicólogos: análise curricular. Psicologia Escolar e Educacional, 5(1), 11-18.

Campos, H. R. (Org.). (2007). Formação em psicologia escolar: realidades e perspectivas. Campinas, SP: Alínea.

Carvalho, M. T. M., \& Sampaio, J. S. (1997). A formação do psicólogo e as áreas emergentes. Psicologia: Ciência e Profissão, 17(1), 14-19.

Catani, A. M., \& Oliveira, J. F. (2002). Educação superior no Brasil: reestruturação e metamorfose das universidades públicas. Petrópolis, RJ: Vozes.

Centofanti, R. (2004). Radeki e a psicologia no Brasil (1982). In M. A. M. Antunes (Org.), História da psicologia no Brasil: primeiros ensaios (pp. 177-208). Rio de Janeiro: EdUERJ; Brasília, DF: Conselho Federal de Psicologia.

Coimbra, C. (1995). Guardiões da ordem: uma viagem pelas práticas psi no Brasil do "milagre". Rio de Janeiro: Oficina do Autor.

Conselho Federal de Psicologia. (1998). Quem éo psicólogo brasileiro? São Paulo: EDICON.

Conselho Federal de Psicologia. (2005). Psicólogo brasileiro: construção de novos espaços (1992). Campinas, SP: Alínea.

Conselho Federal de Psicologia. (2007). Relatório final do VI Congresso Nacional de Psicologia. Brasília, DF. Recuperado em 30 de novembro de 2008, de www.pol.org.br

Dias, C. A. (2001). Considerações sobre elaboração de currículos para formação de psicólogos: a partir de uma perspectiva didática. Psicologia: Ciência e Profissão, 21(3), 36-49.

Dimenstein, M. D. B. (1998). O psicólogo nas unidades básicas de saúde: desafios para a formação e atuação profissionais. Estudos de Psicologia, 3(1), 53-81.

Duran, A. P. (1994). Alguns dilemas na formação do psicólogo: buscando sugestões para superá-los. In Conselho Federal de Psicologia, Psicólogo brasileiro: práticas emergentes e desafios para a formação (pp. 273-310). São Paulo: Casa do Psicólogo.

Esch, C. F., \& Jacó-Vilela, A. M. (2001). A regulamentação da profissão e os currículos de formação psi. In A. M. Jacó-Vilela, A. C. Cerezzo, \& H. B. C. Rodrigues (Öros.), Clio-Psyché hoje: fazeres e dizeres psi na história do Brasil (pp. 17-24). Rio de Janeiro: Relume Dumará; FAPERJ.

Fernandes, M. I. A. (2001). Abandono das instituições: construção de políticas públicas e universidade. Psicologia USP, 12(2). Recuperado em 05 de fevereiro de 2007, de www.scielo.com

Ferreira Neto, J. L. (2004). A formação do psicólogo: clínica, social e mercado. São Paulo: Escuta; Belo Horizonte: Fumed/ FCH.

Francisco, A. L., \& Bastos, A. V. B. (2005). Conhecimento, formação e prática: o necessário caminho da integração. In Conselho Federal de Psicologia, Psicólogo brasileiro: construção de novos espaços (pp. 71-88). Campinas, SP: Alínea.

Gomes, W. B. (1996). Pesquisa e ensino em psicologia: articulações possíveis entre graduação e pós-graduação. In R. M. L. L. Carvalho (Org.), Repensando a formação do psicólogo: da informação à descoberta (pp. 33-50). Campinas, SP: Alínea.

Gomide, P. I. C. (1998). A formação acadêmica: onde existem suas deficiências. In Conselho Federal de Psicologia, Quem é o psicólogo brasileiro? (pp. 69-85). São Paulo: EDICON'

Gonçalves, M. G. M., \& Bock, A. M. B. (1996). Desenhando a psicologia: uma reflexão sobre a formação do psicólogo. Psicologia Revista, 2,141-150.

Guzzo, R. S. L. (2007). Reforma universitária, universidade nova e o futuro da psicologia. Disponível em. Recuperado em 05 de fevereiro de 2007, de www.abepsi.org.br

Holanda, A. F. (1997). Relatório de análise dos processos de abertura de novos cursos de Psicologia. Brasília, DF: Conselho Federal de Psicologia. Recuperado em 30 de novembro de 2007, de www. abepsi.org.br

Instituto Brasileiro de Geografia e Estatística. (2007). População recenseada e estimada, segundo as Grandes Regiões e as Unidades da Federação - 2007. Recuperado em 05 de fevereiro de 2009, de www.ibge.gov.br

lema, C. R. D. (1999). Um estudo teórico sobre a formação do psicólogo organizacional no Brasil. Psicologia: Teoria e Pesquisa, 1(1), 31-41. 


\section{Referências}

Instituto Nacional de Estudos e Pesquisas Educacionais Anísio Teixeira. Recuperado em 30 de novembro de 2007, de www. inep.gov.br

Kodjaoglanian, V. L., Benites, C. C. A., Macário, I., Lacoski, M. C. E. K., Andrade, S. M. O., Nascimento, V. N. A., \& Machado, J. L. (2003). Inovando métodos de ensino-aprendizagem na formação do psicólogo. Psicologia: Ciência e Profissão, 23(1), 2-11.

Landeira-Fernandez, J., \& Primi, R. (2002). Comparação do desempenho entre calouros e formandos no Provão de Psicologia 2000. Psicologia: Reflexão e Crítica, 15(1), 219-234.

Langenbach, M., \& Negreiros, T. C. G. M. (1988). A formação complementar: um labirinto profissional. In Conselho Federal de Psicologia, Quem é o psicólogo brasileiro? (pp. 86-99). São Paulo: EDICON

Lo Bianco, A. C., Bastos, A. V. B., Nunes, M. L. T., \& Silva, R. C. S. (1994). Concepções e atividades emergentes na psicologia clínica: implicações para a formação. In Conselho Federal de Psicologia, Psicólogo brasileiro: práticas emergentes e desafios para a formação (pp. 7-79). São Paulo: Casa do Psicólogo.

Lourenço Filho, M. B. (2004). A psicologia no Brasil (1955). In M. A. M. Antunes (Org.), História da psicologia no Brasil: primeiros ensaios (pp. 71-108). Rio de Janeiro: EdUERJ; Brasília, DF: Conselho Federal de Psicologia.

Maluf, M. R. (1994). Formação e atuação do psicólogo na educação: dinâmica da transformação. In Conselho Federal de Psicologia, Psicólogo brasileiro: práticas emergentes e desafios para a formação (pp. 157-200). São Paulo: Casa do Psicólogo.

Marinho-Araújo, C. M. (2007). A psicologia escolar nas diretrizes curriculares: espaços criados, desafios instalados. In H. R. Campos (Org.), Formação em psicologia escolar: realidades e perspectivas (pp. 17-48). Campinas, SP: Alínea.

Martínez, A. M. (2003). Psicologia e compromisso social: desafios para a formação do psicólogo. In A. M. B. Bock, Psicologia e compromisso social (pp. 143-160). São Paulo: Cortez.

Massimi, M. (1990). História da psicologia brasileira: da época colonial até 1934. São Paulo: EPU.

Matos, M. A. (1988). Produção e formação científica em psicologia. In Conselho Federal de Psicologia, Quem é o psicólogo brasileiro? (pp. 100-122). São Paulo: EDICON.

Matos, M. A. (2000). A definição de diretrizes em uma estruturação curricular em psicologia e o estágio de formação profissional. Psicólogo InFormação, 4(4), 11-24.

Medeiros, J. G. (1989). O currículo como objeto de pesquisa. Psicologia: Ciência e Profissão, 9(1), 16-18.

Mello, S. L. (1989). Currículo: quais mudanças ocorreram desde 1962? Psicologia: Ciência e profissão, 9(1), 16-18.

Moura, E. P. G. M. (1999). A psicologia (e os psicólogos) que temos e a psicologia que queremos: reflexões a partir das Propostas de Diretrizes Curriculares (MEC/SESU) para os cursos de graduação em psicologia. Psicologia: Ciência e Profissão, 19(2), 10-19.

Natário, E. G. (1999). A pesquisa na formação do psicólogo. In C. Witter (Org.), Ensino de psicologia (pp. 25-40). Campinas, SP: Alínea.

Noronha, A. P. P. (2002). Os problemas mais graves e mais freqüentes no uso dos testes psicológicos. Psicologia: Reflexão e Crítica, 15(1), 135-142.

Noronha, A. P. P. (2003). Docentes de psicologia: formação profissional. Estudos de Psicologia, 8(1), 169-173.

Noronha, A. P. P. (2006). Formação em avaliação psicológica: uma análise das disciplinas. Interação em Psicologia, 10(2), 245-252.

Olinto, P. (2004). A psicologia experimental no Brasil (1944). In M. A. M. Antunes, História da psicologia no Brasil: primeiros ensaios (pp. 25-31). Rio de Janeiro: EdUERJ; Brasília, DF: Conselho Federal de Psicologia.

Organização Mundial de Saúde, \& Conselho Federal de Psicologia. (2001). Pesquisa perfil do psicólogo brasileiro. Recuperado em 30 de novembro de 2007, de www.pol.org.br

Patto, M. H. S. (2005). Compromisso político e formação do psicólogo: considerações a partir da luta antimanicomial. In M.
H. S. Patto, Exercícios de indignação: escritos de educação e psicologia (pp. 71-85). São Paulo: Casa do Psicólogo.

Penna, A. G. (1992). História da psicologia no Rio de Janeiro. Rio de Janeiro: Imago.

Pereira, F. M., \& Pereira Neto, A. P. (2003). O psicólogo no Brasil: notas sobre seu processo de profissionalização. Psicologia em Estudo, 8(2), 19-27.

Pereira, S. L. M. (1996). A formação profissional dos psicólogos: apontamentos para um estudo. In M. H. S. Patto, Introducão a psicologia escolar (pp. 424-430). São Paulo: Casa do Psicólogo.

Pessotti, I. (2004). Notas para uma história da psicologia no Brasi (1988). In M. A. M. Antunes, (Org.), História da psicologia no Brasil: primeiros ensaios (pp. 209-227). Rio de Janeiro: EdUERJ; Brasília, DF: Conselho Federal de Psicologia.

Pfromm Netto, S. (2004). A psicologia no Brasil (1981). In M. A. M. Antunes (Org.), História da psicologia no Brasil: primeiros ensaios (pp. 140-175). Rio de Janeiro: EdUERJ; Brasília, DF: Conselho Federal de Psicologia.

Pfromm Netto, S. (2007). Psicologia, psicologias: velhos e novos olhares. Algumas considerações sobre o passado, o presente e o futuro da psicologia como ciência, profissão e ensino. Psicologia em Pesquisa, 1(1), 8-13.

Primi, R., Landeira-Fernandez, J., \& Ziviani, C. (2003). O provão de psicologia: objetivos, problemas, conseqüências e sugestões. Psicologia: Teoria e Pesquisa, 19(2), 109-116.

Rivlin, L. G. (2003). Olhando o passado e o futuro: revendo pressupostos sobre as inter-relacões pessoa-ambiente. Estudos de Psicologia (Natal), 8(2), 215-220.

Rocha Jr., A. (1999). Das discussões em torno da formação em psicologia às diretrizes curriculares. Psicologia: Teoria e Prática 1(2), 3-8.

Rosas, P., Rosas, A., \& Xavier, I. B. (1988). Quantos e quem somos. In Conselho Federal de Psicologia, Quem é o psicólogo brasileiro? (pp.32-48). São Paulo: EDICON.

Silva, S. M. C. (2004). Algumas reflexões sobre a arte e a formação do psicólogo. Psicologia: Ciência e Profissão, 24(4), 100-111.

Saviani, D., Patto, M. H. S., Guedes, T. M. C. Serio, T. M. P. A Pessoti, I., Maldos, P. R. M., Bock, A. M. B., \& Malvezzi, S. (1984). Política educacional e formação profissional do psicólogo. Psicologia: Ciência e Profissão, 4(2), 24-33.

Souza, L. C. G. (2005). O ensino da psicologia social e suas representações: a formação do saber e o saber em formacão. Dissertação de Mestrado em Psicologia, Universidade Federal do Rio de Janeiro, Rio de Janeiro.

Witter. C. (Org.). (1999). Ensino de psicologia. Campinas, SP: Alínea

Witter, G. P., \& Ferreira, A. A. (2005). Formação do psicólogo hoje. In Conselho Federal de Psicologia, Psicólogo brasileiro: construção de novos espaços (pp. 15-39). Campinas, SP: Alínea.

Witter, G. P., Gonçalves, C. L. C., Witter, C., Yukimitsu, M. T. C. P., \& Napolitano, J. R. (2005). Formação e estágio acadêmico em psicologia no Brasil. In Conselho Federal de Psicologia, Psicólogo brasileiro: construção de novos espaços (pp. 41-69). Campinas, SP: Alínea.

Yamamoto, O. H. (2000). A LBD e a psicologia. Psicologia: Ciência e Profissão, 20(4), 30-37.

Yamamoto, O. H. (2006). Graduação e pós-graduação em psicologia: relações possíveis. Revista Brasileira de Pós-Graduação, 3(6), 270-281.

Yamamoto, O. H., \& Tourinho, E. Z. (2006). Situação da pósgraduação na área da psicologia SNPG e APCN. 2006. Recuperado em 05 de fevereiro de 2009, de www.anpepp.org.br

Yukimitsu, M. T. C. P. (1999). A formação do psicólogo: considerações gerais. In C. Witter (Org.), Ensino de psicologia (pp. 13-24). Campinas, SP: Alínea.

Zanelli, J. C. (1994). Movimentos emergentes na prática dos psicólogos brasileiros nas organizações de trabalho: implicações para a formação. In Conselho Federal de Psicologia, Psicólogo brasileiro: práticas emergentes e desafios para a formação (pp. 81-156). São Paulo: Casa do Psicólogo.

Zanelli, J. C. (2002). O psicólogo nas organizações de trabalho. Porto Alegre: Artmed. 